\title{
CYBORGS Y DISEÑO DEL CUERPO: ARTE Y TECNOLOGÍA, UNA MIRADA DESDE FÉLIX DUQUE ${ }^{1}$
}

\author{
RONALD DURÁN ALLIMANT \\ Universidad de Playa Ancha, Valparaíso - Chile
}

\begin{abstract}
RESUMEN: En este artículo se analizan las relaciones entre arte, tecnología y cuerpo, teniendo como marco de análisis el pensamiento del filósofo español Félix Duque. En primer lugar, consideramos la concepción del cuerpo como máquina y su derivación actual en la noción de cyborg. En segundo lugar, mostramos cómo la concepción del cuerpo-máquina se hace parte del body art de Stelarc y del arte carnal de Orlan, quienes plantean el diseño del cuerpo dada su obsolescencia. En tercer lugar, presentamos las críticas de Duque a estos ciberartistas y en general a los planteamientos transhumanistas y posthumanistas. Finalmente, comparamos la metáfora del «cyborg» en Broncano con la «filosofía de la técnica de la naturaleza» de Duque, poniendo de relieve la necesidad de plantear y explicitar la cuestión política implícita en el diseño del cuerpo y la «libre creación».
\end{abstract}

PALABRAS CLAVE: arte; tecnología; cuerpo; cyborg; diseño.

\section{Cyborgs and Body Design: Art and Technology, a View from Félix Duque}

ABSTRACT: In this article we analyze the relationships between art, technology and body, taking as a framework for the analysis Spanish philosopher Felix Duque's ideas. In the first place, we consider the conception of the body as a machine and its current derivation in the notion of cyborg. Secondly, we show how the conception of the body-machine becomes part of Stelarc's body art and Orlan's carnal art, who propose the design of the body because of its obsolescence. In the third place, we expose Duque's criticisms of these cyber-artists and, in general, of the transhumanist and posthumanist approaches. Finally, we compare the metaphor of the «cyborg» in Broncano with Duque's «philosophy of the technique of nature», highlighting the need to raise and make explicit the political issue implicit in the design of the body and the "free creation".

KEY WORDS: art; technology; body; cyborg; design.

\section{INTRODUCCIÓN}

La noción de cyborg o ciberorganismo, tanto en el arte como en la tecnología, sobre todo en los años 80, puso en tensión las relaciones entre lo natural y lo artificial, lo biológico y lo tecnológico, que los desarrollos científico-técnicos han ido reconfigurando de maneras cada vez más radicales, volviendo realidad posibilidades que parecían mera ciencia ficción. Científicos, ingenieros, artistas y partidarios de posiciones transhumanistas y posthumanistas han puesto de relieve cuestiones como la obsolescencia del cuerpo y su posible diseño o rediseño, su extensión o perfeccionamiento, superando así los límites de la evolución meramente biológica con una evolución tecnológica. A la base de estas

1 La presente investigación ha sido posible gracias al financiamiento otorgado por el proyecto FONDECYT Postdoctoral $\mathrm{N}^{\circ} 3160241$ de CONICYT, del que el autor del presente escrito es el investigador responsable. 
concepciones está la idea del cuerpo como máquina, concepción del cuerpo que va mucho más allá del siglo XX, hasta los comienzos de la modernidad. Analizaremos aquí las relaciones entre arte, tecnología y cuerpo, tomando algunas ideas de la filosofía de Félix Duque como marco de análisis. En primer lugar, consideraremos la concepción del cuerpo como máquina y su derivación actual en la noción de cyborg. En segundo lugar, mostraremos cómo esta concepción del cuerpo se hace parte del body art de Stelarc y del arte carnal de Orlan, quienes plantean el diseño o rediseño del cuerpo dada su obsolescencia. En tercer lugar, presentaremos las críticas de Duque a estos ciberartistas y en general a los planteamientos transhumanistas y posthumanistas. Finalmente, compararemos la metáfora del «cyborg» en Broncano con la «filosofía de la técnica de la naturaleza» de Duque, poniendo de relieve la necesidad de plantear y explicitar la dimensión histórica y la cuestión política implícitas en el diseño del cuerpo y la «libre creación».

\section{LA CONCEPCIÓN DEL CUERPO COMO MÁQUINA Y EL CYBORG (CIBERORGANISMO)}

Durante los siglos XVII y XVIII vemos constituirse con fuerza una concepción del cuerpo que sigue vigente en nuestros días: el cuerpo concebido como máquina. En este periodo se produce una proliferación de autómatas, de máquinas automáticas en iglesias, teatros, palacios, jardines. Tal es su abundancia que Montaigne en viaje por Italia en 1580 afirma al observar una pequeña escena representada por un búho autómata y un grupo de aves mecánicas: «Todas estas invenciones, o algunas similares, producidas por las mismas reglas de la naturaleza [...] las he visto en otra parte» (Riskin, 2016: 30), con un cierto aire de hastío por la repetición de estos artilugios. Estos autómatas, relojes, molinos, figuras humanas y animales en movimiento, cuevas artificiales (grottos), aunque diversos en forma, obedecían a un mismo principio: diversas partes o engranajes en funcionamiento mecánico coordinado. A diferencia de los instrumentos o herramientas manuales, una pala por ejemplo, los autómatas poseen una suerte de autonomía o independencia funcional. El movimiento que los pone en acción no establece el funcionamiento o la forma de los movimientos coordinados que tienen lugar en la máquina.

El cuerpo no sería más que una máquina, tal como afirma Descartes, más sutil que las máquinas humanas pero no por ello menos maquinal. En su tratado Sobre el hombre, Descartes expone de manera ejemplar la concepción del cuerpo orgánico bajo el modelo mecánico:

«Supongo que el cuerpo no es otra cosa que una estatua o máquina de tierra a la que Dios forma [...y] también dispone en su interior todas las piezas requeridas para lograr que se mueva, coma, respire y, en resumen, imite todas las funciones que nos son propias [...] Conocemos relojes, fuentes artificiales, molinos y otras máquinas similares que aun habiendo sido realizadas por el hombre, tienen capacidad para moverse de modos diversos en virtud de sus 
propios medios [...] No me detendré describiendo los huesos, los nervios, los músculos, las arterias, el estómago, el hígado, el bazo, el corazón, el cerebro ni todas las otras piezas que componen esta máquina» (Descartes, 1990: 22-3).

Máquinas y autómatas constituyen en los siglos XVII y XVIII el paisaje, por así decir, que ofrece imágenes y metáforas, que permiten concebir y afirmar que el cuerpo en realidad es una máquina. Incluso aunque autores como Leibniz establecieran una diferencia esencial entre máquinas orgánicas y máquinas mecánicas, no sólo una diferencia de grado como en Descartes (Durán, 2017: 85), la máquina seguirá siendo el respecto a partir del cual el cuerpo es concebido. Máquinas y autómatas se convierten en la manera de entender el fundamento mismo de lo corporal. Los cuerpos visibles estarían constituidos por cuerpos invisibles que en el fondo serían equivalentes en cuanto a notas y estructuración. Al desdibujar los límites entre lo natural y lo artificial, esta concepción del cuerpo dio lugar a dos líneas de desarrollo que siguen vigentes hasta nuestros días. Por una parte, concebir el cuerpo como máquina permite por ejemplo estudiarlo por separado, como conjunto de sistemas o partes con cierto grado de independencia, estudiarlo además a partir de sus componentes mecánicos o químicos. Desde esta perspectiva, por ejemplo el corazón no es más que una bomba. Esta idea está presente en nuestra concepción de la medicina, y en la realización de trasplantes. Por otra parte, concebir el cuerpo como máquina abre la posibilidad de producir máquinas que imiten lo orgánico. En esta línea encontramos la creación de androides, máquinas que buscan imitar a los seres humanos, como por ejemplo los trabajos de Jacques de Vaucanson, o los famosos androides de la familia Jaquet Droz en el siglo XVIII (Riskin, 2016: 129ss).

Un paso importante en la concepción del cuerpo como máquina, lo constituye la extensión de la noción de autómata o máquina automática. Las máquinas del siglo XVIII sólo podían realizar una tarea específica y no eran capaces de ajustarse a cambios en el ambiente. La cibernética de los años 40 y 50 del siglo XX, da el paso en esta línea con la máquina autorregulada (Winner, 1948). Los sistemas autorregulados, constituyen mecanismos de retroalimentación que permiten el control a través de la comunicación de mensajes (información). Estos desarrollos vuelven cada vez más difusos los límites entre lo artificial y lo natural. Lo natural y lo artificial son concebidos ahora como sistemas de retroalimentación que actúan en función de un valor esperado. El cuerpo humano, los animales, las máquinas cibernéticas serían equivalentes en lo esencial, independiente de sus diferencias materiales: todos funcionarían como mecanismos de auto-regulación u homeostasis. Esta transgresión de límites queda de manifiesto en la configuración de la noción de cyborg. En el artículo de M. Clynes y N. Kline, «Cyborgs and Space» (1960), dedicado a la adaptación fisiológica y psicológica del ser humano al espacio exterior, se introduce el término «cyborg». La idea es adaptar las funciones orgánicas (concebidas como parte de sistemas homeostáticos) del ser humano a medioambientes extremos, a través de la incorporación de artefactos tecnológicos. Se trata de una adaptación 
tecnológicamente mediada. Como preguntan los autores: «¿Cuáles son algunos de los aparatos necesarios para crear el sistema hombre-máquina auto-regulado?» (Clynes y Kline, 1960: 27). El cyborg constituiría una extensión que liberaría al ser humano en el viaje espacial, que es a la vez un reto tecnológico y un reto espiritual (la última frontera). «Si el hombre en el espacio, además de volar su vehículo, debe continuamente chequear cosas y realizar ajustes solamente para mantenerse vivo, se vuelve un esclavo de la máquina. El propósito del Cyborg, y de sus sistemas homeostáticos, es ofrecer un sistema organizacional en el que tales problemas tipo-robot se realicen automática e inconscientemente, dejando al hombre libre para explorar, para pensar y para sentir» (Clynes y Kline, 1960: 27). Los aspectos de libertad (superación de los límites impuestos por el cuerpo) y exploración (en un sentido casi religioso) serán cruciales para entender las ideas trans y post-humanistas y el arte asociado a ellas en lo que llamamos el diseño del cuerpo, tal como veremos más adelante. De esta manera, cada vez más el cuerpo queda abierto a un diseño completo, tal como si la propia corporalidad pudiera ser escrita o construida como una obra de arte. La concepción mecánica del cuerpo conduce a concebirlo como algo libremente diseñable. El desarrollo de nuevas máquinas y tecnologías va reactualizando la comprensión mecánica del cuerpo, y ampliando cada vez más la «libertad creativa», hasta el punto de concebir la posibilidad de un diseño absoluto del cuerpo.

Durante los años 70 y 80 el cyborg se transforma en una figura del cine y la televisión, una figura de ciencia ficción. En los años 70 tenemos la serie The Six Million Dollar Man (conocida como El hombre nuclear en Latinoamérica), que presenta un piloto de pruebas de la NASA que sufre un grave accidente y es reconstruido como un hombre biónico (corre más rápido, tiene una vista más poderosa y un oído más agudo que lo normal). Ejemplos tales como Terminator, Robocop, Blade Runner, y en los 90 Ghost in the Shell, muestran que los límites entre lo humano y lo maquinal, entre lo supuestamente natural y lo artificial se van haciendo borrosos. Dentro de las películas mencionadas, Robocop constituye probablemente la mejor expresión de estos límites ambiguos entre lo humano y lo maquinal. ¿Dónde termina la máquina y dónde comienza lo humano? Visualmente la película deja abierta esta pregunta, pues aunque el policía-robot se reconoce a partir de su memoria como el policía humano muerto Murphy, en una aplicación de la noción de identidad de Locke, está al mismo tiempo limitado por las leyes impuestas por su programación (recordemos que no puede matar al Presidente de la compañía). En este sentido, este ser ambiguo no es pura voluntad sino la compleja y tensa unidad de hombre y máquina. Esta unidad compleja, queda completamente desbaratada en el remake de esta película en 2014, donde se muestra con claridad el interior de Robocop y este interior completamente transparente permite identificar donde comienza y donde termina lo humano y lo robótico. La destrucción de la compleja unidad deja en claro que el director de esta versión no tuvo la misma sutileza de Paul Verhoeven. Robocop es además una figura clave porque muestra que la dimensión mental no actúa completamente absuelta controlando 
su cuerpo a voluntad, sino que constituye un momento de una unidad humano-máquina que configura un ámbito nuevo de posibilidades, ni puramente humano ni puramente maquinal. Esta ambigüedad está presente también en Blade Runner, tanto en la película como en el libro. En ambos casos aparece el papel clave de la memoria como elemento de identidad y humanidad. Estas obras plantean la incómoda pregunta: «¿Cuál es el criterio de demarcación de lo humano, si han dejado de serlo tanto el cuerpo como la psique?» (Duque, 2007b: 1). Para Duque una respuesta podría ser «el ser amante de extranjerías y lejanías»(2007b: 2).

En 1985, la filósofa estadounidense Donna Haraway, publica «A Cyborg Manifesto: Science, Technology, and Socialist-Feminism in the Late Twentieth Century» (Haraway, 1995: 251ss). Este artículo tuvo gran influencia y contribuyó a posicionar el concepto de cyborg en el ámbito de discusión académica como metáfora de la condición humana a finales del siglo XX. "A finales del siglo XX —nuestra era, un tiempo mítico—, todos somos quimeras, híbridos teorizados y fabricados de máquina y organismo; en resumen, somos cyborgs» (1995: 254). El cyborg no es una imagen para entender el futuro, como podría suceder en la ciencia ficción, sino para entender el presente. En el artículo, Haraway trata de construir un «irónico mito político fiel al feminismo, al socialismo y al materialismo» (1995: 251), articulando varias líneas de análisis. La ironía como concepto fundamental «se ocupa de las contradicciones que, incluso dialécticamente, no dan lugar a totalidades mayores, se ocupa de la tensión inherente a mantener juntas cosas incompatibles, consideradas necesarias y verdaderas» (1995: 253). En el cyborg como metáfora de la condición humana diferencias como natural y artificial se mantienen en tensión (ironía) sin posibilidad de resolución. Es una metáfora para un mundo sin «unidad originaria», sin "paraíso perdido», sin «edad de oro», sin «caída», o «totalidad en que las partes se someten a una unidad superior». Metáfora para un mundo en que se asumen las diferencias como fuente de riqueza y posibilidades. «El $c y$ borg elude el paso de la unidad original, de identificación con la naturaleza en el sentido occidental» (1995: 255). Haraway piensa esta metáfora o mito como fuente de rebelión y liberación política y de superación de un tipo de feminismo esencialista que apela a la naturaleza o al origen. Fuera de toda apelación a la naturaleza, el cyborg implica «un canto al placer en la confusión de fronteras y a la responsabilidad en su construcción»(1995: 254). El mito cyborg «trata de fronteras transgredidas, de fusiones poderosas y de posibilidades peligrosas que gentes progresistas pueden explorar como parte de un necesario trabajo político [...] un mundo cyborg podría tratar de realidades sociales y corporales vividas en las que la gente no tienen miedo de su parentesco con animales y máquinas, ni de identidades permanentemente parciales, ni de puntos de vista contradictorios» (1995: 262-3). Nos construimos, por así decir, a cada instante a pedazos.

Los movimientos transhumanistas y posthumanistas, que constituyen una extensión de la concepción del cuerpo-máquina y del cyborg, tienen como supuesto básico la creencia y afirmación de que las tecnologías (electrónicas, 
informáticas, biológicas, nanotecnológicas, etc.), constituyen el medio adecuado para alcanzar sueños o deseos que el ser humano largamente ha buscado: trascendencia del cuerpo, perfeccionamiento corporal, ideales humanistas, libertad, control y dominio absolutos, inmortalidad (Diéguez, 2017; Hottois, 2014, Ferry, 2017). Las posiciones van desde aquellas que sólo creen estar perfeccionando lo natural, por eso serían transhumanistas, una suerte de posición alquímica, y aquellas que creen estar yendo más allá de lo humano, posthumanistas (aunque las diferencias entre denominaciones no siempre es estricta), en ambos casos caracterizando de manera negativa lo que el ser humano ya es, en tanto debe ser superado. Perfección mienta por tanto dos cosas distintas, extensión o potenciación de lo que ya se tiene, o bien, transformación radical por incorporación de algo completamente otro, deviniendo lo humano, por tanto, una entidad esencialmente distinta a la que ya es.

En su dimensión ontológica, el cyborg ya no es puramente una noción técnica, científica o de ficción, sino una condición ontológica, que incluso puede considerarse no sólo propia de los seres humanos de finales del siglo XX, sino del ser humano desde siempre. Es en este marco en donde se concibe la posibilidad de un diseño completo del cuerpo, idea que ha sido impulsada por los movimientos transhumanistas y posthumanistas. El cyborg es entendido como:

«Cyborg. Cybernetic-organism [organismo-cibernético]. La fusión de lo orgánico y lo maquínico, o la ingeniería de una unión entre sistemas orgánicos separados [...] Fusión de lo evolucionado y lo desarrollado, esta integración del constructor y lo construido, estos sistemas de carne que muere y circuitos que no mueren, y de células vivientes y artificiales, han sido llamados de muchas maneras: sistemas biónicos, máquinas vitales, cyborgs» (Gray et al., 1995: 2).

\section{ObSOLESCENCIA y Diseño DEL CUERPo EN El ARTE CONTEMPORÁNEO: STELARC y ORLAN}

En el ámbito del arte, la noción de cyborg y las relaciones cuerpo y máquina, o cuerpo y tecnología, han sido fecundas en artistas como Stelarc y Orlan. A esta altura estos artistas constituyen referentes ya clásicos al tratar las relaciones entre arte, cuerpo y tecnología, y han contribuido fuertemente a difundir las ideas trans y post-humanistas, compartiendo con ellas el supuesto básico de que las tecnologías actuales son los medios adecuados para perfeccionar y extender el cuerpo, superando sus limitaciones.

El artista australiano Stelarc (1946-) es parte del llamado body art (arte del cuerpo) y de lo que se ha denominado arte cibernético. En sus performances, suspensiones y alteraciones físicas, es el propio cuerpo del artista el que se convierte en objeto de manipulación y creación, el cuerpo mismo está sujeto a diseño. La afirmación de Stelarc de que «el cuerpo está obsoleto» se ha convertido en el slogan de su propuesta artística. Esta expresión ha encontrado concreción en proyectos artísticos tales como: Third Hand, en donde un brazo mecánico 
de forma humana es ajustado al brazo derecho del artista, otorgándole así una mano adicional; Exoskeleton, en el que el artista controla un dispositivo mecánico de seis piernas (una suerte de araña mecánica); o bien Ear on Arm, proyecto en el que Stelarc se incorpora una oreja artificial en el brazo, dotada de un micrófono. Todos estos proyectos muestran distintas maneras en las que la obsolescencia del cuerpo podría superarse extendiéndolo, modificándolo, diseñándolo, según se desee. Ahora bien, ¿por qué afirma Stelarc que el cuerpo está obsoleto? ¿Qué entiende por cuerpo? ¿Y para quién está obsoleto? En nuestros tiempos de «obsolescencia programada», la noción de obsolescencia no se reduce simplemente al no funcionamiento de una cosa. La obsolescencia puede ser no sólo funcional sino simbólica. Incluso funcionando, es decir, cumpliendo aún su finalidad técnica, algo puede considerarse obsoleto porque deja de cumplir las expectativas o deseos de una persona. Así, la afirmación de la obsolescencia implica inmediatamente un para quién. ¿Qué dice Stelarc al respecto?

Algunos textos breves de Stelarc, pueden ayudarnos a responder estas preguntas. En «Absent Bodies» el artista nos dice lo siguiente:

«Operamos sobre todo como cuerpos ausentes. ESTO PORQUE UN CUERPO ESTÁ DISEÑADO PARA INTERACTUAR CON SU MEDIOAMBIENTE — sus sensores están abiertos-al-mundo (comparado con su inadecuado sistema de vigilancia interna). La movilidad y navegación del cuerpo en el mundo requiere esta orientación hacia lo exterior. Su ausencia se ve aumentada por el hecho de que el cuerpo funciona de manera habitual y automática. LA CONCIENCIA ES A MENUDO LO QUE OCURRE CUANDO EL CUERPO NO FUNCIONA BIEN. / Reforzados por la convención cartesiana, la conveniencia personal y el diseño neurológico, la gente opera meramente como mentes, inmersas en nieblas metafísicas. El sociólogo P. L. Berger hace la distinción entre «tener un cuerpo» y «ser un cuerpo». COMO SUPUESTOS AGENTES LIBRES, LAS CAPACIDADES DE SER UN CUERPO ESTÁN CONSTREÑIDAS POR TENER UN CUERPO. / Nuestras acciones e ideas están esencialmente determinadas por nuestra fisiología. Estamos en los límites de la fisiología, no sólo porque estamos en los límites del lenguaje. La filosofía está fundamentalmente fundamentada en nuestra fisiología».

Se manifiestan en estas afirmaciones posiciones que mezclan elementos de la pre-compresión del Dasein heideggeriano, con un materialismo biologicista que critica la preeminencia de la mente sobre el cuerpo, y la clásica distinción fenomenológica entre Leib (cuerpo vivido) y Körper (cuerpo como objeto), que Stelarc atribuye al sociólogo P. L. Berger. Con esta amalgama, más que superar el dualismo, Stelarc parece reafirmarlo enfatizando la determinación fisiológica de la conciencia, la mente y la filosofía. El cuerpo consistiría así en una estructura de ajuste con el ambiente que la mente olvida e ignora y que sólo considera al fallar este ajuste. Esta falta de ajuste es clave en la comprensión de la obsolescencia del cuerpo afirmada por Stelarc. Así en «Obsolete Bodies» nos dice: 
«Es hora de cuestionar si un cuerpo bípedo que respira con visión binocular y un cerebro de $1400 \mathrm{cc}$ es una forma biológica adecuada. No puede hacer frente a la cantidad, complejidad y calidad de la información que ha acumulado; se ve intimidado por la precisión, velocidad y potencia de la tecnología y está biológicamente mal equipado para hacer frente a su nuevo entorno extraterrestre. / El cuerpo no es una estructura muy eficiente ni muy duradera. A menudo funciona mal y se fatiga rápidamente; su rendimiento está determinado por su edad. Es susceptible a las enfermedades y está condenado a una muerte segura y temprana. Sus parámetros de supervivencia son muy escasos: puede sobrevivir solo semanas sin comida, días sin agua y minutos sin oxígeno./ La FALTA DE DISEÑO MODULAR del cuerpo y su sistema inmunológico hiperactivo dificultan la sustitución de los órganos defectuosos. Podría ser el colmo de la locura tecnológica considerar el cuerpo obsoleto en forma y función, pero podría ser el colmo de las realizaciones humanas. Porque solo cuando el cuerpo toma conciencia de su posición actual puede mapear sus estrategias post-evolutivas. / Ya no se trata de perpetuar la especie humana mediante la REPRODUCCIÓN, sino de mejorar las relaciones entre hombres y mujeres mediante la interfaz hombre-máquina. EL CUERPO ESTÁ OBSOLETO. Estamos al final de la filosofía y la fisiología humana. El pensamiento humano retrocede al pasado humano».

Así pues, el cuerpo estaría obsoleto porque no es capaz de ajustarse al ambiente técnico de nuestra época. La glorificación del cuerpo que encontramos en «Absent bodies» se reemplaza ahora por la enumeración de sus insuficiencias, repitiendo así Stelarc la clásica concepción del ser humano y de su corporalidad como deficientes, a diferencia de los otros animales que estarían adecuadamente ajustados a su ambiente. Notemos el vocabulario empleado por Stelarc para describir las insuficiencias corporales: mal funcionamiento, bajo rendimiento, carencia de precisión, velocidad y potencia adecuadas. Estos términos parecen describir más bien una máquina, por ejemplo, un automóvil, más que un cuerpo humano. Se evidencia claramente así la concepción mecánica del cuerpo presente en el discurso de Stelarc, y con ello la afirmación del dualismo cuerpo-mente. El cuerpo humano parece ser ahora un mero instrumento pobremente ajustado al ambiente tecnológico humanamente construido, y por lo tanto, mal ajustado a los deseos y expectativas de la propia mente humana. Por lo tanto, hay que reacondicionar, rediseñar la máquina-cuerpo. El cuerpo es ahora un «objeto de diseño», ¿para quién? Paradójicamente para la mente humana, que parece a-corporal, aun cuando Stelarc intente esconder esta mente como una suerte de cuerpo que en extraño ejercicio reflexivo se mira a sí mismo y se considera obsoleto. Se mantiene así el dualismo y la preeminencia de la mente que Stelarc parecía primero criticar. Así parece quedar refrendado en su texto «Redesigning the Body»:

«Ya no es significativo ver el cuerpo como un sitio para la psique o lo social, sino más bien como una estructura a ser monitoreada y modificada, el cuerpo no como un sujeto sino como un objeto. NO UN OBJETO DE DESEO SINO UN OBJETO PARA DISEÑAR [...] Como objeto, el cuerpo puede ser 
amplificado y acelerado, logrando velocidad de escape planetario. Se convierte en un proyectil post-evolutivo, partiendo y diversificándose en forma y función».

Stelarc plantea así la obsolescencia del cuerpo y busca con su obra superar los límites que este cuerpo obsoleto impone, límites que le resultan sofocantes. En palabras que parecieran dichas por Descartes, o por el doctor Victor Frankenstein, Stelarc describe la situación actual del cuerpo, teniendo en cuenta el desarrollo de las tecnologías bio-médicas e informáticas, de la siguiente manera:

«Vivimos en una época de exceso e indiferencia. De aumento prostético y sistemas operativos extendidos. Una época de Órganos sin Cuerpos. De órganos esperando cuerpos. Existe ahora una proliferación de componentes biocompatibles tanto en substancia como en escala que permite a la tecnología estar unida e implantada en el cuerpo. Los órganos son extraídos e intercambiados. Los órganos son manipulados e insertados. La sangre circulando en mi cuerpo hoy podría estar circulando en tu cuerpo mañana. Óvulos son fertilizados por esperma que estuvo congelada alguna vez. Existe ahora la posibilidad de que células de la piel de cuerpos femeninos puedan ser rediseñados en células espermáticas. El rostro del cuerpo de un donante se transforma en un tercer rostro en el receptor. Brazos pueden ser unidos o amputados desde un cuerpo muerto y unidos a un cuerpo vivo. Los cadáveres pueden preservarse para siempre con plastinación, mientras que los cuerpos en estado de coma pueden mantenerse indefinidamente en sistemas de soporte vital. Los cuerpos suspendidos criogénicamente esperan la reanimación en un futuro imaginado. Los muertos, los casi muertos, los no muertos y los aún por nacer existen simultáneamente. Esta es una época del Cadáver, del Comatoso y de la Quimera. La quimera es el cuerpo que realiza con realidades mixtas. Un cuerpo biológico, aumentado con tecnología y que funciona con sistemas virtuales telemáticos. La quimera es una encarnación alternativa. El cuerpo actúa con indiferencia. Indiferencia en lugar de expectativa. Una indiferencia que permite que ocurra algo diferente, que permite un despliegue, en su propio tiempo y con su propio ritmo. Una indiferencia que permite que al cuerpo estar suspendido con ganchos en su piel, que permite la inserción de una escultura en su estómago y que permite construir una oreja quirúrgicamente y desarrollar células madre en su brazo» (Stelarc, "Excess and Indifference. Alternate Body Architectures»).

Stelarc describe todas las posibles manipulaciones que el «paradigma» del cuerpo máquina hace posibles. Sus palabras describen una situación que podríamos llamar hipermecanicismo.

Por su parte, la artista francesa Orlan (1947-), que también parte del arte corporal, se ha dado a conocer sobre todo por sus performances quirúrgicas, su llamado carnal art, que a diferencia del body art enfatiza el placer y no el dolor. En ellas, al igual que Stelarc, Orlan manipula, modifica y diseña su propio cuerpo de maneras diversas, y también considera que el cuerpo está obsoleto en tanto no se ajusta al ambiento tecnológico actual: 
«Como yo, el artista australiano Stelarc piensa que el cuerpo está obsoleto; no responde a la situación. Nos movemos a la velocidad de las cucarachas; pero es que somos cucarachas que tienen sus memorias en los ordenadores que controlan aviones o coches que nosotros mismos diseñamos, aunque nuestro cuerpo no esté diseñado para su velocidad y todo vaya cada vez más deprisa. Nos encontramos en la frontera de un mundo para el que no estamos preparados ni mental ni físicamente» (Orlan, 2000: 24).

A partir del año 1990, Orlan inició una serie de performances quirúrgicas (las primeras tituladas «La reencarnación de Santa Orlan» e «Imagen - nuevas imágenes»), en las que se sometía a intervenciones de cirugía plástica modificando su rostro para incorporar en él características particulares de algunos modelos de belleza de la plástica occidental (Diana, Mona Lisa, Psique, Venus, Europa). Estas intervenciones son concebidas como un autorretrato en sentido clásico:

«El arte carnal es un autorretrato en el sentido clásico, pero realizado mediante las posibilidades tecnológicas. Se encuentra entre la desfiguración y la refiguración. Esta inscripción en la carne, es una función de nuestro tiempo. El cuerpo se ha convertido en un "ready-made modificado", ya no se considera como lo ideal que representó una vez; el cuerpo ya no es nunca más ese ready-made ideal que fue tan satisfactorio firmar»(Orlan, «Arte Carnal»).

Con su concepción de autorretrato Orlan espera que la imagen interior sea exteriorizable, una nueva imagen que se logra gracias a las nuevas tecnologías. En este ejercicio de retrato creemos discernir, no obstante, un dualismo implícito, entre una imagen interna y otra externa de sí mismo. Las nuevas tecnologías permitirían que la imagen externa se ajustara mejor a la imagen interna. El texto «El vestido» de la psicoanalista Eugénie Lemoine Luccioni, ilustra a juicio de Orlan todas sus performances-operaciones. En este texto encontramos afirmaciones como: «La piel es decepcionante [...] en la vida sólo contamos con nuestra piel [...] hay "maldonne [malas cartas, error]" en las relaciones humanas porque nunca se es lo que se tiene [...] nunca tengo la piel de quien soy. No hay excepciones para esta regla porque nunca soy lo que tengo» (citado en Orlan, 2000: 21). En referencia a esta cita, Orlan afirma: «Leyendo este texto pensé que hoy en día empezamos a reducir las diferencias que nos separan, sobre todo con ayuda de la cirugía, y por lo tanto podría ser posible transformar la imagen interna en la imagen externa»(Orlan, 2000: 21). El cuerpo aparece como absolutamente plástico, abierto a la posibilidad de ser diseñado en función de la imagen que se quiere exteriorizar o plasmar: «Podemos decir que voy de lo real a lo virtual dado que hago operaciones/performances para transformarme, reconstruirme, desfigurarme a mí misma — es estar a medio camino entre la reconstrucción y la desfiguración» (palabras extraídas de video Metamorphosis).

Ahora bien, Orlan no elige los modelos de belleza para incorporarlos en su rostro y alcanzar una suerte de belleza en sí (como afirmará erróneamente Duque, tal como veremos más adelante), sino como una crítica a los modelos de belleza impuestas a las mujeres por los hombres. Su trabajo es un acto consciente y reflexivo de rechazo a estos modelos, no su afirmación. Su trabajo va 
en contra de «los estándares de belleza, contra los dictados de la ideología dominante que se imprimen cada vez más en las carnes femeninas y masculinas. La cirugía estética es uno de los elementos mediante el cual el poder del hombre sobre el cuerpo de la mujer puede cobrar más fuerza» (Orlan, 2000: 24). Sin embargo, Orlan no rechaza la cirugía estética, pues esta tecnología, ofrecería la posibilidad de plasmar la identidad escondida.

«En el pasado nuestra esperanza de vida era de cuarenta a cincuenta años. Hoy en día, ha pasado a setenta u ochenta años - y aumenta sin cesar-. A todos nos asalta un sentimiento de extrañeza ante un espejo, sentimiento que aumenta con el envejecimiento y, para algunas personas, se vuelve insoportable. El uso de la cirugía estética es muy positivo en estos casos, mientras llegue una medicación que sea eficaz. Naturalmente la cirugía estética no debe convertirse en algo obligatorio. Una vez más la presión social no debe pesar más que el deseo individual y el autorretrato. Utilizar la cirugía no es algo natural, ya sea o no estética, pero tomar antibióticos para evitar morir por una infección tampoco lo es. Es una de las posibles elecciones de nuestro siglo, que se constituye como una experiencia» (2000: 24).

En su libro Ontología Cyborg, la filósofa española Teresa Aguilar, evalúa positivamente los trabajos de Stelarc y Orlan como expresión de la exaltación de la materialidad del cuerpo (2008: 117). A su juicio: «El arte centrado en el propio cuerpo del artista pretende su rematerialización expresando a través de él las problemáticas sociopolíticas y sexuales» $(2008: 118)^{2}$. O como afirma Orlan: «Mi trabajo y sus ideas encarnadas en mi carne hacen que me haga preguntas sobre la situación del cuerpo en nuestra sociedad y su porvenir en las próximas generaciones, a través de las nuevas tecnologías y de las próximas manipulaciones genéticas»(Orlan, 2000: 21). Actitud que se condice con su concepción del arte.

«El arte que me interesaba, pertenece a la resistencia. Debe agitar los cimientos de nuestras convicciones apriorísticas, trastocar nuestros pensamientos, estar fuera de las normas, deber estar fuera de la ley; estar contra el arte y el orden burgués. No está allí para mecernos, para volvernos a dar lo que ya conocemos; debe arriesgarse, incluso corriendo el riesgo de no ser aceptado en un principio. Se desvía de las normas y es en sí mismo un proyecto de sociedad» (Orlan, 2000: 20-1).

2 Los trabajos de Stelarc u Orlan ponen de relieve la influencia de la ciencia y la tecnología no sólo en la concepción del cuerpo sino en su manipulación y diseño. Manipulaciones que, sin embargo, no son propias solamente del arte carnal o del body art, sino que forman parte de posibilidades ya ampliamente disponibles: cirugía plástica, trasplantes, prótesis, etc. La modelo Amy Mullins, una suerte de «cyborg real», afirma en una entrevista que la amputación opcional será una opción, sobre todo en el ámbito del deporte (ver documental Un homme presque parfait [Homo Technologicus] (2011) de Cecile Denjean). También podemos encontrar el diseño del cuerpo en ámbitos médicos, prótesis, trasplantes de órganos, o bien modificaciones genéticas, lo que Nikolas Rose llama «biopolítica molecular», gracias a los desarrollos de la ingeniería genética (Rose, N. (2012), Políticas de la vida: biomedicina, poder y subjetividad en el siglo XXI, La Plata, UNIPE). Elección de características de los hijos, úteros y órganos artificiales aunque aún suenan a ciencia ficción cada vez están más presentes. 
Duque, sin embargo, juzgará de manera distinta la obra de estos artistas y por extensión la de los movimientos transhumanistas y posthumanistas que ayudaron a difundir.

3. Críticas de Duque al diseño del cuerpo en el arte contemporáneo y a las POSICIONES TRANSHUMANISTAS Y POSTHUMANISTAS EN GENERAL

En su artículo «De cyborgs, superhombres y otras exageraciones»(2003), Félix Duque se muestra escéptico acerca de las consecuencias radicales que Stelarc y Orlan parecen derivar de sus trabajos, a quienes considera una suerte de «marionetas del entertainment cibergológico» (2003: 177), y critica de manera general las posiciones transhumanistas y posthumanistas. Como argumento general de la crítica tenemos la acusación de que más que una exaltación del cuerpo, encontraríamos en estos artistas y movimientos, una suerte de neognosticismo, es decir, un rechazo del cuerpo, que implicaría a su vez un dualismo mente-cuerpo. Este hipercartesianismo o gnosticismo, dejaría en evidencia, según Duque, «el odio que sienten estos nuevos cyborgs por su propio cuerpo humano, y sus proclamas para trascender ese "despojo", indigno de la nueva era» (2003: 173). «No es extraño [...] que primero la religión y luego [...] alguna rama hodierna tecnoingenieril, empeñada $-\mathrm{y}$ con bastante éxito, por lo demás - en sustituir con ventaja a la ya anticuada religión positiva, hayan insistido e insistan en el carácter degradante, humillante del cuerpo y de la carne: algo propio de esclavos» (Duque, 2007a: 3).

Al mismo tiempo, la búsqueda de un diseño o control absoluto del cuerpo, demostraría que éste es considerado como una mera masa amorfa, completamente disponible y dispuesta a toda manipulación que el yo desee voluntariamente ejercer sobre ella. Como afirma Duque:

«La libertad productora se expresa (se impone) pues en el mundo como un acto arbitrario, o sea un mandato de la voluntad, pero racionalmente proyectado y dirigido. Tal acto signa y define ya de antemano aquello que ha de ser producido, como si se aplicara sobre una materia absolutamente plástica, maleable. En una palabra, es el resultado de un designio. Así, cosas, seres vivos y hombres (por ahora sólo parcialmente, virtualmente o en efigie) dejan tendencialmente de ser considerados como entes naturales que nacen, se desarrollan, se reproducen y mueren (según la célebre definición hace muchos años impartida en las escuelas) para ser tenidos por productos de diseño, el cual, por su parte, no sería sino la plasmación fenoménica del designio (o sea, de aquel acto de voluntad guiado por la recta razón; recta, por tender al máximo beneficio con el mínimo coste)»(2008: 102-3).

El cuerpo sería algo puramente pasivo sin actividad propia ${ }^{3}$, y por lo tanto, estaría siempre a completa disposición. Detrás de todos estos intentos

3 Crítica que ya Leibniz hacía a la concepción puramente mecánica del cuerpo en Descartes. Si el cuerpo carece de actividad intrínseca entonces es equivalente a no ser (Durán, 2017). 
subyacería, tal como ya dijimos, una ontología dualista que enlazaría con las éticas tradicionales (control de las pasiones o del cuerpo por la razón o la voluntad). En ellos la materia, el cuerpo, no es más que una amalgama pasiva en espera de forma. En el caso particular de Stelarc, Duque afirma: «Stelarc trata su cuerpo como si fuese un objeto de diseño, a modo de material básico que ha de ser profundamente modificado por la máquina para acceder a un Cuerpo amplificado y transhumano»(2003: 174). En el caso de Orlan, su rechazo del cuerpo y su dualismo de base estarían expresados en su afirmación de que «el cuerpo no es más que un disfraz», lo que la llevaría, según Duque, a:

«la recomposición —en principio, indefinida- del propio cuerpo mediante sesiones de cirugía plástica retransmitidas como si de un espectáculo deportivo se tratase, con objeto de que Madame Orlan pueda llegar a ser la Mujer única, el resumen de la belleza...convencional y ramplonamente machista, puesto que las intervenciones que se han hecho en su cara tenían como finalidad "reproducir" en este collage vivo: "la frente de la Gioconda, los ojos de la Psique de Gérôme, la nariz de una Diana de la Escuela de Fontainebleau, la boca de la Europa de Boucher y la barbilla de la Venus de Botticelli [...] Madame Orlan [...] quiere diluirse en los fragmentos de la Belleza Universal, según los criterios turísticos propios, por ejemplo, de una Guía Michelin [...]" Otras mujeres sufren por no parecerse lo suficiente a Barbie» (2003: 176-7).

Ahora bien, a pesar de lo que afirma Duque, hay que tener en cuenta, tal como dijimos antes, que Orlan busca con su arte carnal criticar los modelos machistas de la belleza femenina, no incorporarlos y reproducirlos de manera acrítica, buscando una suerte de Belleza en sí. En este punto la crítica de Duque no acierta. Sí creemos que es posible hacer la crítica de dualismo a Orlan, en tanto sus performances-operaciones son concebidas como un autorretrato que externaliza una imagen interna que se considera más auténtica, más propia, pero oculta. El cuerpo es manipulado y diseñado para que plasme la forma, identidad o imagen interna. Sin embargo, nuestro cuerpo nunca es una masa puramente pasiva disponible para su libre manipulación por una voluntad o mente despegada, y por otra parte, quien diseña nunca es un ente puramente espiritual que planifique sin mácula, sino que posee en sí mismo una dimensión material y corporal.

«Nuestro cuerpo, a pesar de todos los aderezos y modificaciones tecnoartísticos que ese soporte recibe, forma parte de la naturaleza y difícilmente puede existir sin ese medio ambiente al que nos estamos refiriendo constantemente. Sólo que mi cuerpo es "mío" (nos decimos, sin saber a ciencia cierta qué queremos decir con ello, pero seguros de esa posesión, cuando quizás debiéramos estarlo de lo contrario: es nuestro cuerpo quien nos posee); sé en efecto que él -mi cuerpo- es parte de la naturaleza cuando ejecuta movimientos de fuera a dentro (ingerir, deglutir, respirar) o de dentro a fuera (con sus deyecciones varias). Pero, dada su originaria esquivez, ni puedo verlo a él en su estado "natural" (cuando los otros lo vean ya será demasiado tarde para mí: estaré de cuerpo presente), ni puedo tampoco ver el de mis semejantes como si fueran cuerpos, sin más (en el trabajo en serie y en la prostitución 
—emparentados en esto, y en otras muchas cosas más-, se utilizan los cuerpos por parcelas y según rendimiento, no en su nuda exposición natural; en la medicina, el cuerpo es visto como un conjunto — más bien mal avenido- de órganos; y en las variadas técnicas de la biopolítica, el cuerpo es leído como si fuera un conjunto de díscolos soportes para la inscripción en ellos de la Ley)» (Duque, 2008: 47-8).

El propio Stelarc ofrece un interesante ejemplo de la no disponibilidad absoluta del cuerpo. No puede tener todo el tiempo el tercer brazo que se agrega, sólo en las performances, porque es demasiado pesado. La oreja que se injerta en el brazo se infectó y tuvo que sacársela. Los sueños de ilimitación, de una voluntad absuelta se ven limitados por el propio cuerpo. El diseño del cuerpo al que apuntan Stelarc u Orlan intenta ser una libre creación ilimitada, una suerte de constructivismo absoluto. El cuerpo sin embargo, tiene ciertas características reales, limitaciones de resistencia, de peso, de funcionamiento orgánico, etc., que establecen sus límites a las posibles manipulaciones del cuerpo ${ }^{4}$. Las ideas de control absoluto del cuerpo criticadas por Duque, quedan bien expresadas en un libro reciente de Polona Tratnik, Conquest of Body: Biopower with Biotechnology (2017), cuya tesis es que la exploración del cuerpo humano (y en esto no sólo su contemplación sino su intervención usando tecnología) tendría como objetivo último obtener conocimiento del cuerpo para conquistarlo. La exploración del cuerpo tendría una conexión intrínseca con el poder, dado que el conocimiento es constitutivo del poder sobre el cuerpo (¿poder de quién?).

La afirmación del diseño absoluto, en su doble momento de imponer un orden o disposición de partes, y de establecer un designio o destino, conllevaría por tanto, el olvido del momento no disponible, de lo incontrolable, de aquello que resiste y permite al mismo tiempo el orden o designio. «El Arte ha reconocido, en la propia aplicación técnica, una resistencia y cerrazón ínsita en la naturaleza, pero que la desfonda y abisma, haciéndola por ello, en su raíz, indisponible» (Duque, 2008: 52).

Dentro de este deseo de control absoluto del cuerpo encontramos la búsqueda de la inmortalidad, es decir, el deseo de vencer la última resistencia. Ésta es una de las ideas más comunes al hablar de la intervención o perfeccionamiento tecnológico del cuerpo o de la vida, y deja en evidencia la carga religiosa presente en gran parte de los discursos trans o post-humanistas, carga religiosa que encontramos al hablar o concebir la tecnología en general (ver el libro de David Noble, La religión de la tecnología de 1999). Promesa de inmortalidad que Duque rechaza en "¿Cuál será el futuro del cuerpo humano?», desde diversas perspectivas: la posible disminución de la tasa de natalidad, la carga para las familias, pero sobre todo el tedio que implicaría la repetición de lo mismo;

4 Sin embargo, estas limitaciones podrían ser consideradas, como hacen muchos transhumanistas, una mera cuestión de hecho, no un límite infranqueable. Pueden a su favor mostrar las modificaciones corporales inimaginables sólo décadas atrás y que ahora son posibles. Por ejemplo, la posibilidad de fecundar fuera del útero materno, o la posibilidad de mantener cuerpos con vida, que están «muertos» desde una perspectiva cerebral, etc. 
tedio que tendría un carácter insoportable (2007b). Un tedio similar al mencionado por Duque lo podemos encontrar en la falta de sentido y el suicidio del millonario en tiempo, al comienzo de la película In Time (Duque, 2011). Agrega Duque en este mismo escrito: «A mi particular entender, ello [la inmortalidad tecnológicamente conseguida] implicaría — si es que alguna vez sucede- una mutación radical en el ser humano, que hasta ahora ha sido y sigue siendo (lo quiera o no) un ser-que-está-a-la-muerte» (Duque, 2007b). Ahora bien, más que un argumento en contra de la inmortalidad tecnológicamente lograda, que es como aparece en el texto citado, esta afirmación podría apoyar el discurso de trans y post-humanistas, al menos de aquellos que plantean una especie nueva más allá del homo sapiens. Pues de conseguir la inmortalidad ya no seríamos humanos sino más bien posthumanos.

Tanto como la mortalidad, el dolor aparece también como otra condena corporal de la que haríamos bien en despojarnos, sin tomar en cuenta la dimensión positiva del dolor. Duque cita a Hegel para resaltar este punto: «Sentir dolor es privilegio de naturalezas superiores; cuanto más alta sea la naturaleza tanta más desdicha se sentirá. El gran hombre tiene grandes necesidades, junto con el impulso de superarlas (es aufzuheben). Las grandes gestas provienen únicamente de un hondo dolor anímico» (citado en Duque, 2007a: 26) Y analizando la cita de Hegel, afirma:

«Esta concepción choca, sin duda, con la trillada senda que considera al cuerpo como instrumento y como vestido. ¿Cómo se va a soportar un "vestido” que duele? ¿No será acaso preferible confeccionarse para uno mismo un traje indoloro, y más: renovable ad libitum, sin necesidad de esperar (y encima sólo en algunos casos) al regalo post mortem de un corpus gloriosum a imagen del prototipo celeste? Ahora bien, ¿cuál es el instrumento indoloro por excelencia, sino la máquina? [...] la tentación para el hombre moderno [...] consistirá, no sólo en utilizar la máquina para ordenar y transformar el mundo externo, sino para cambiar su cuerpo, hasta el extremo de insertar la máquina en esa su propia configuración animal; el resultado: una voz mecánica, artificial, que ni siente ni padece, surgida del hondón programado del nuevo prototipo que reemplaza en su carácter ideal, modélico, al Varón de Dolores: el organismo cibernético, o cyborg» (Duque, 2007a: 27).

El dolor aparece no sólo como una condición negativa, que debiera eliminarse, sino como condición de la propia actividad humana. Algo similar sucede con la noción de melancolía que es a la vez una condición negativa, como podría serlo la depresión hoy, y la fuente de la creatividad artística (ver por ejemplo Saturno y la melancolía (1994) de E. Panofsky, F. Saxl y R. Klibansky). Las posiciones trans y post-humanistas parecen olvidar esto, afirmando con claridad la eliminación del dolor, el sufrimiento y la enfermedad, tal como lo encontramos en el punto 1 de la «Declaración transhumanista»: "La humanidad es susceptible de ser afectada profundamente por la ciencia y la tecnología en el futuro. Prevemos la posibilidad de agrandar el potencial humano venciendo el envejecimiento, las limitaciones cognitivas, el sufrimiento involuntario y nuestro confinamiento al planeta Tierra» (More y Vita-More, 2013: 54). Encontramos en esto una 
afirmación naif de lo humano, que delimita con claridad y distinción lo bueno y lo malo, olvidado la complejidad y la mezcla muchas veces indiscernible entre lo uno y lo otro, entre normal y anormal, entre salud y enfermedad.

El dualismo de fondo que hace del cuerpo algo puramente pasivo, y el control absoluto que podría ejercerse sobre él, control que permitiría superar la muerte y el dolor, tienen como base el dualismo natural-artificial. Paradójicamente, los ciberartistas Stelarc y Orlan, y los defensores del trans y post-humanismo, en su glorificación de la tecnología, de lo artificial, afirman lo mismo que aquellos que rechazan la tecnología apelando a la naturaleza, a saber: la radical separación de lo natural y lo artificial. La supuesta hibridación no sería tal, sino siempre la supeditación de uno de los polos (lo natural o lo artificial) al otro. La crítica que Duque hace a J. D. García Bacca y su Elogio de la técnica (1968), en Filosofía de la técnica de la naturaleza (1986) ${ }^{5}$, puede extenderse a las posiciones trans y post-humanistas analizadas. Olvidar que la naturaleza es, a la vez, ocasión para y producto de, el trabajo o la técnica humana, conduce a una unilateral posición de lucha de la técnica y el trabajo humano en contra de la naturaleza.

«Por esta vía acabamos en desaforado antropocentrismo: "lo natural, su propia naturaleza incluida, es para el hombre actual simple y bruto material para fines inventados por él, y con fines que él se propone por decisiones inventadas" [García Bacca en Elogio de la técnica]. Parece así que la invención sea producto libérrimo de la mente humana, tan desenganchada de su cuerpo como de los cuerpos. Triunfo de una Técnica tan voluntariosa como antinatural. Esto, apenas hay que decirlo, es una continuación anacrónica de la creencia en el Progreso» (Duque, 1986: 22; 2019: 23).

La apelación a lo natural y la consiguiente idea de que lo natural es algo separado del ser humano mismo, pero sometible a su voluntad viene de:

"[...] considerar a la naturaleza como entidad separada e independiente del hombre, pero en última instancia sometible a él [...] El hombre no utiliza el medio (como si éste se dejara hacer, inerte), ni se adapta a él: no existe adaptación en ninguna parte, a menos que entendamos por ello interacción dinámica en continua transformación [...] El hombre -no el Hombre, sino las distintas comunidades étnico-históricas- se transforma a sí mismo al

5 Nuestro artículo fue elaborado antes de la tercera edición de esta obra, publicada en marzo de 2019 (Duque, 2019). Hemos consultado esta edición y en lo sustancial no obliga a modificaciones importantes ni en las ideas expresadas ni en las citas utilizadas en este artículo. Sólo destacamos que en la nueva edición Duque evita utilizar los términos «Técnica» y «Hombre» con mayúsculas. Por ejemplo, en la edición de 1986 dice: «Triunfo de una Técnica tan voluntariosa como antinatural» (22), mientras que en 2019 dice: «Triunfo absoluto de una técnica tan voluntariosa como antinatural» (23). En otro ejemplo tenemos en la edición de 1986: «El hombre — no el Hombre, sino las distintas comunidades étnico-históricas - se transforma a sí mismo al transformar su medio, su circunstancia [...]» (24), mientras que en la de 2019 dice: «El hombre —o mejor, las distintas comunidades etnohistóricas- se transforma a sí mismo al transformar su medio, su circunstancia [...]» (24). 
transformar su medio, su circunstancia, porque —orteguianamente hablando- si no las salva a ellas no se salva él mismo» (Duque, 1986: 23-4).

Otro argumento en contra de las posiciones trans y post-humanistas por parte de Duque, yacería en el improbable e inverosímil interés en modificaciones radicales por parte de personas e instituciones.

«[...] cuando llegue el momento de la fácil comercialización de trasplantes, bancos de esperma, intervenciones genéticas, etc., y una vez pasado el inevitable entusiasmo por esas nuevas posibilidades, ¿se lanzará la gente en masa a sufrir la "gran transformación"? Yo particularmente no lo creo, y no sólo por el coste de las intervenciones [...] no creo que ni la ciencia ni las instituciones estatales (o supraestatales) fomenten una transformación masiva del cuerpo humano y de su longevidad. Además, y en el plano individual, ese "longevo sin fronteras" estaría siempre cada vez más pendiente de no ser afectado, herido, conmocionado de cualquier modo por el entorno, así que al final optaría por vivir como ya lo hiciera Howard Hughes [o los ricos en In Time, diríamos nosotros]» (Duque, 2007b).

Nos parece que en este caso Duque yerra el diagnóstico. Los indicios actuales no parecen ir en la dirección que sus palabras describen, al contrario. El negocio ilegal de venta de órganos a nivel mundial, el sostenimiento de humanos en estado vegetal, las cirugías plásticas de diversa índole, las diversas técnicas de fertilización artificial, el doping en el deporte, la inserción de chips para distintas funciones (ver el documental de DW, Hombres cibernéticos (2017) de Luisa Wawrzinek), por mencionar sólo algunos casos, evidencian el creciente interés en la modificación del cuerpo. Así pues, el panorama futuro dibujado en la película Repo Men (2010), en donde órganos artificiales se venden como un ítem más en un mall o multitienda, parece más probable que un statu quo de no intervención. De hecho, la importancia que han adquirido los discursos tanto transhumanistas como posthumanistas, mostrando que no se trata de una mera moda pasajera, queda reflejada con claridad en la serie de informes elaborados tanto por Estados Unidos como por la Unión Europea, a saber: «Tecnologías convergentes para el mejoramiento del desempeño humano. Nanotecnología, biotecnología, información tecnológica y ciencia cognitiva» (EE. UU., 2002), «Tecnologías convergentes. Dando forma al futuro de las sociedades europeas) (UE, 2004), «La mejora humana»(UE, 2009). Además de estos informes, la existencia de la Asociación Transhumanista Mundial, o del Instituto Futuro de la Humanidad, en los que juega un rol importante el filósofo Nick Bostrom, muestran que el mero desprecio o la indiferencia intelectual no son suficientes frente al avance de estos movimientos. De hecho, libros recientes como los de Gilbert Hottois (2014), Luc Ferry (2017) y Antonio Diéguez (2017) buscan evaluar de manera seria las propuestas planteadas por transhumanistas y posthumanistas.

Frente al optimismo de autoras como Haraway, quien en la hibridación implicada por el cyborg, ve la posibilidad de una superación irónica de diferencias 
largamente arraigadas (Haraway, 1995: 275-6), Duque ofrece un balance negativo de las posiciones analizadas:

"Lo que algunas tendencias actuales de la cibermanía (más que "cibergología") nos presentan deja poco lugar a la esperanza de una rebelión postsocialista —o al menos insumisión, como en Total Recall ("Desafío total")— de las razas, géneros, y marginados de toda suerte, que se aprovecharán de la expansión del sistema para boicotearlo desde dentro. Más bien al contrario, parece que estuviéramos asistiendo en estas postrimerías del siglo y del milenio a una extrañísima suerte de tecnoespiritualidad laica como reacción extrema frente a la más bien empalagosa New Age con sus ensoñaciones sobre la Gran Madre Naturaleza, las "buenas vibraciones" cósmicas y demás arrebatos de los "hijos de las flores". En las antípodas de este panteísmo tecnonaturalista, propio de los años sesenta-setenta, encontramos ahora un cyberpunk paradójicamente hipercartesiano, o mejor: decididamente gnóstico, dado el odio que sienten estos nuevos cyborgs por su propio cuerpo humano, y sus proclamas para trascender ese "despojo", indigno de la nueva era» (Duque, 2003: 173).

4. La FILOSOFí́a DE LA «TÉCNICA DE LA NATURALEZA» Y LA METÁFORA DEL «CYBORG»: LA CUESTIÓN POLÍTICA DEL DISEÑO DEL CUERPO

La posición crítica de Duque ha sido criticada a su vez. Así, el filósofo español, Fernando Broncano, en su libro La melancolía del ciborg (2009), se refiere en términos críticos al artículo de Duque «De cyborgs, superhombres y otras exageraciones» (2003):

«En un texto más bien displicente, Félix Duque examina lo que llama la creciente cibermanía, a la que acusa de ser una nueva forma de cartesianismo, basándose en la "obsolescencia" de lo corporal que fue alguna vez proclamada por el tan extraño como provocativo ser, Stelarc, y que ha sido ya convertida en la acusación extensiva a toda forma cultural que atienda a los fenómenos relacionados con lo cyborg [...] el presunto odio al cuerpo del ciborg en la enfermedad de la anorexia le sirve a Duque para reivindicar una opulencia muy a lo Balzac, expresada en una forma modesta, como corresponde a un intelectual moderado, de superhombre nietzscheano que observa el discurrir del tiempo con aristocrática distancia» (Broncano, 2009: 29-30).

Más allá de la apelación ad hominen, Broncano parece querer ubicar a Duque dentro de aquellos que habrían recibido con suspicacia la superación de ciertas dicotomías (Broncano, 2009: 29) que la noción de cyborg traería (según afirma Broncano siguiendo a Haraway). Broncano identifica dos argumentos principales, que serían recursos habituales de aquellos críticos de los cyborgs y sus partidarios. El primer argumento sería la acusación de dualismo y el implícito rechazo del cuerpo que estaría presente en quienes defienden las posiciones transhumanistas y posthumanistas. El segundo argumento sería la acusación de que estas posturas, que buscan superar los límites del cuerpo humano, son una mera extensión del capitalismo neoliberal, serían una 
extensión, un ejemplo más, de la continua búsqueda de mayor disponibilidad de productos a elección, esencial para todo consumir actual (Broncano, 2009: 29ss). Broncano trata de mostrar que estas acusaciones son infundadas, al menos cuando estas acusaciones se aplican a los trabajos efectivos de quienes se dedican con seriedad al "paradigma» transhumanista (ingenieros en robótica o en inteligencia artificial):

«Es cierto que hay algunos pronunciamientos salidos de tono en los libros de divulgación de algunos de los investigadores responsables de los avances en robótica [por ejemplo Moravec, a quien también critica Duque en (2007a: 29)] [... ] Pero no es cierto en absoluto el abandono de la dimensión corpórea. Al contrario, los laboratorios de robótica han sido lugares donde se han hecho explícitas las dependencias de los aspectos informacionales y los corpóreos [...] Ni el cuerpo ni la mente humanos están obsoletos» (Broncano, 2009: 35).

Por su parte, la acusación de extensión del capitalismo omnívoro, o de la lógica del capitalismo contemporáneo, podría ser considerada una nueva versión de los tan manidos determinismo tecnológico y autonomía de la tecnología, habituales en los autores de lo que podemos llamar la «filosofía clásica de la tecnología» (Heidegger, Jonas, Ellul, entre otros), y que por tanto, quitan de las manos de los agentes racionales la labor de crear y dirigir los caminos futuros de la tecnología y la sociedad.

«La lógica del capitalismo estaría alcanzando a la propia esencia de lo humano convirtiendo a los seres humanos en ciborgs, productos destinados a quedar obsoletos en las diversas olas de consumo [...] Para esta forma de crítica, pues, el aceptar la categoría de los ciborgs como parte de nuestra metafísica de la realidad no sería sino una forma de rendición, abierta o solapada, a la lógica de la producción, a la irresistible invasión del capital [...] Si el capital planifica, tendría que ser planificado por algún agente, él mismo una identidad ciborg [...]; si no planifica, es que se está concibiendo como una fuerza autónoma, causal, como una fuerza "natural" en el viejo sentido de lo natural como lo opuesto al nomos, a la convención y a la voluntad colectiva» (Broncano, 2009: 34).

Duque usa en mayor o menor medida los argumentos mencionados por Broncano, tal como hemos visto más arriba. Paradójicamente, a pesar de las críticas, Broncano y Duque están de acuerdo en la crítica al dualismo, aunque el primero ve en los desarrollos tecnológicos serios una apreciación del cuerpo, que Duque no encuentra, al menos en los discursos de divulgación de algunos de sus representantes. Ahora bien, esto no es trivial. Son estos discursos los que configuran el imaginario que permite solicitar y conseguir recursos para implementar proyectos en ciencia y tecnología. Puede que los ingenieros en robótica o en inteligencia artificial por principio no rechacen el cuerpo ni crean en su obsolescencia (algo que no resulta tan claro), o puede que de hecho tengan que considerar el cuerpo, dadas las limitaciones de las tecnologías actuales, o la resistencia que la materialidad del cuerpo ofrece a su manipulación. No obstante, lo relevante desde una perspectiva social y política más amplia no 
son las creencias particulares o la práctica efectiva, sino el discurso con el que esas prácticas se divulgan y se presentan, las promesas que se asocian a ellas y la evaluación de riesgos que implican. Este discurso es el que contribuirá al financiamiento o no de estas investigaciones. Baste pensar en lo que ha pasado con la industria espacial estadounidense después de terminado el boom de la carrera espacial de los años 60.

Ahora bien, para comprender las críticas de Broncano, hay que entender las diferencias de enfoque respecto a la tecnología y su posible control que tiene respecto a Duque. En su libro La melancolía del ciborg (2009), Broncano plantea la noción de "cyborg» como adecuada para analizar nuestra condición contemporánea, siguiendo la estela de Haraway. ¿Qué son los ciborgs para Broncano y por qué su melancolía?

«[...] somos seres que habitan en el viaje a un mundo subjetivo que llamo mundo de la frontera, un lugar imaginario de refugio que acoge formas variadas de resistencia. La figura que mejor los representa [a estos seres de la frontera] es la de los ciborgs, seres que no saben lo que son, seres a los que no les dejan saber lo que son porque son interpretados por categorías dominantes, hechas de dicotomías que tienen en sí la semilla de la dominación y la exclusión» (Broncano, 2009: 15).

«Los humanos somos seres hechos por prótesis. Toda prótesis molesta. Es la molestia de lo nuevo, la invasión de los hábitos y los patrones que se han convertido en otra manera de ser [...] Las prótesis desclasan, desclasifican, transforman: nos convierten en galateas que habitan nuevos espacios, en seres desarrraigados y exiliados a nuevas fronteras del ser» (Broncano, 2009: 20-1).

«[...] los ciborgs sufren melancolía; una melancolía que no es una enfermedad del alma sino fruto del desarraigo. Los ciborgs tienen nostalgia de un mundo al que no pueden volver. Su desarraigo es tan completo que la nostalgia se transfigura en distancia y en identidad desarraigada, en desarraigo de la identidad. Su existencia protésica les hace saber de su extrañeza en el mundo y esa extrañeza es el origen de la melancolía» (Broncano, 2009: 24).

Los cyborgs son seres de frontera, esencialmente desarraigados, sin unidad o identidad primigenia, de ahí en cierta medida su melancolía, y no se reconocen en su fluidez categorial, porque son encasillados, por las categorías dominantes.

Sobre todo, la noción de cyborg se plantea para superar la dicotomía natural-artificial. El cyborg por su condición inextricablemente híbrida no puede ser asignado ni a lo natural ni a lo artificial de manera unilateral, ni siquiera a ambas a la vez, en tanto lo natural y lo artificial son categorías del pasado, y el cyborg una categoría del futuro, incorporando una promesa de posibilidad futura. La categoría de cyborg es en cierta medida un operador de posibilidades.

«Los ciborgs no pueden ser encerrados en algunas categorías [...] Las categorías de lo artificial y lo natural están ligadas al tiempo pasado [...] la división entre lo natural y lo artificial está encadenada a ciertas políticas de valoración [...] Las categorías de lo natural y lo artificial pertenecen a esta 
forma de clasificar objetos con consecuencias políticas [...] La dicotomía entre lo natural y lo artificial es la que separa las dependencias entre lo atribuible a lo humano y lo externo [...] La dicotomía instaura así el límite de lo político, de la praxis y de la moral» (Broncano, 2009: 27-8).

Broncano asocia con claridad el problema político que está implícito en las categorías de lo natural y lo artificial, las cuestiones de poder y dominación presentes en la asignación de la pertenencia a estas categorías. La pertenencia a lo natural o lo artificial no es algo «natural», simplemente dado, sino producto de un proceso de asignación o delimitación. Este proceso de asignación es el que no aparece, sin embargo, en el libro de Broncano, en su conexión con el cyborg, como producto de esta delimitación, incorporando la dimensión histórica y las distribuciones de poder implicadas en nuestra condición híbrida.

A nuestro juicio, el análisis de Broncano y con ello la propia metáfora del «cyborg» tal como la emplea adolece de dos falencias principales. En primer lugar, la oscilación o ambigüedad de la denominación «cyborg» que en ocasiones se aplica de manera general a todos los seres humanos, y en ocasiones, en un uso más restringido, a un grupo particular, el de los excluidos o dominados (aunque nunca queda claro quién domina y quién es sometido, aunque asumimos que siempre son cyborgs los que están en juego). Si la denominación «cyborg» es aplicable de manera indiferenciada, tanto a un turista, como a un inmigrante, como a quien se le trasplanta un órgano, la noción de cyborg pierde peso como concepto filosófico, refiriéndose igualmente a cualquier objeto que pueda considerarse de alguna manera híbrido. En segundo lugar, una falencia ya mencionada que nos parece aún más grave: la falta de un análisis histórico y político, una suerte de genealogía, de la producción de los cyborgs, que ponga en evidencia las diferencias políticas e históricas presentes entre todos aquellos que parecen entrar en la denominación cyborg. Se olvidan así los procesos que dan lugar a la hibridación. El turista, por ejemplo, es un inmigrante pasajero, por así decir, gracias a su dinero y tiempo, es un híbrido por voluntad propia y en busca de placer; mientras que el inmigrante es un híbrido forzado, por sus ideas políticas, por ejemplo, o por carencia económica; finalmente, quien recibe un órgano, puede ser alguien que esperó largamente en una lista de espera, o bien alguien que pagó gran cantidad de dinero para conseguir un órgano en el mercado ilegal. Al considerar el proceso que da lugar a los cyborgs, saltan a la vista diferencias notables, que obligan, en última instancia, a un análisis político y ético. Da la impresión que Broncano en un afán de escapar de determinismos tecnológicos, históricos, o de constructivismos sociales, termina por aplicar ideas de evolución biológica a la historia humana, sólo que ahora el darwinismo social del siglo XIX, está adecuadamente actualizado y remozado con palabras tales como deriva genética, nicho ecológico, etc. Como él mismo afirma: "Los ciborgs ya no son humanos. Los ciborgs saben que las especies son construcciones inestables en el río histórico de la deriva genética» (Broncano, 2009: 25). Ahora bien, Broncano no deja en manos de las mutaciones y 
el fitness evolutivo, la regulación y el control de la tecnología, sino en manos de la racionalidad tecnológica y el diseño colectivo, que a través de adecuadas políticas de ciencia y tecnología, convenientemente consensuadas entre ingenieros y ciudadanos, permitirían orientar el desarrollo científico y técnico en direcciones socialmente deseables (Broncano, 2006; 2000).

A pesar de la crítica de Broncano, Duque estaría de acuerdo con él en que es necesario superar la dicotomía natural-artificial, y en la cuestión política implicada en la asignación o delimitación de lo natural y lo artificial. No olvidemos que de manera contemporánea a Haraway, Duque publica su Filosofía de la técnica de la naturaleza (1986), en el que afirma la imposibilidad de establecer una dicotomía natural/artificial, no sólo respecto a la época actual, sino desde que el ser humano es humano. «No hay línea de demarcación entre Naturaleza y Cultura, sino una diferencia de perspectiva de un mismo plexo de referencias» (Duque, 1986: 26; 2019: 27). Lo que llamamos natural nunca es puramente natural, pues «[...] tendemos a considerar como natural a todo lo perteneciente a un estadio de relación entre fuerzas productivas, relaciones sociales de producción y creación de procesos inventivos ya superado, y con el que nos encontramos como sustrato de nuestro hacer» (Duque, 1986: 23). Tampoco nuestro cuerpo es algo puramente natural, como ya ponían de relieve las «técnicas del cuerpo» estudiadas por el antropólogo Marcel Mauss (1936). Tanto la «técnica de la naturaleza» de Duque como la noción de «cyborg» (defendida por Haraway y Broncano), apuntan a una crítica a la «apelación a la naturaleza» (que sirve de garante de lo bueno, lo bello, lo normal, etc.), con la que se busca establecer una dicotomía radical entre lo natural y lo artificial.

Sin embargo, Duque no estaría de acuerdo, en que la noción de cyborg sea la adecuada para la superación de esta dicotomía. Ciertamente, es escéptico respecto al excesivo entusiasmo despertado por los cyborgs, entusiasmo reflejado por ejemplo en el «Manifiesto para cyborgs» de Haraway, en donde los cyborgs con su carácter irónico, juegan un papel transgresor y de rebelión, poniendo en tensión categorías dicotómicas largo tiempo establecidas, tales como natural/ artificial, hombre/mujer, etc. Alimentan sobre todo el escepticismo de Duque, la vaguedad de estas consignas «para cambiar radicalmente el mundo y los ejes de un Poder asentado justamente en la coyunda de la nueva tecnología informática con el redescubrimiento de la animalidad del cuerpo humano» (Duque, 2003: 173), escepticismo con el que estamos completamente de acuerdo. Para Duque, el cyborg es un autómata, pero no es autónomo. No se programa a sí mismo. Carece de conciencia, no en el sentido de «darse cuenta» de lo que hace, sino en el más radical y moralmente relevante de: "conciencia de lo que está haciendo y voluntad para proponerse libremente fines y alteraciones» (Duque, 2003: 169). Esto hace a su vez que los cyborgs no puedan tener hogar, pues no pueden habitar, incapaces de abrir sendas, en sentido heideggeriano: «[...] el ya adveniente genocyborg [...] podría ciertamente vivir en una casa, pero no habitar en un hogar» (Duque, 2002: 141). La no pertenencia, el desarraigo que para Broncano es una virtud, por así decir, de la condición cyborg, en tanto 
permite su no asignación en categorías fijas, resulta algo negativo para Duque, la demostración del carácter no-humano del cyborg.

Tampoco estaría de acuerdo Duque con Broncano, en que el control y diseño de una racionalidad tecnológica colectiva y de consenso sea suficiente para encauzar los desarrollos tecnológicos. Duque se inclina más por una posición de corte heideggeriano, escéptico respecto a las capacidades de control pleno de la racionalidad humana. Persiste siempre una dimensión de «indisponibilidad» que no puede resolverse o reducirse a una cuestión de control racional, ya sea político o de otro tipo. Así pues, la colaboración simultánea de Hombre y Técnica «no se logra sino raras veces, ya sea por "indisposición" de lo que hace al caso o por falta de preparación e iniciativa de quien hace caso, o sea, del técnico "buen entendedor"» (Duque, 2001: 17-8). Ahora bien, ¿Cómo se determina este ajuste? ¿Quién decide si el ajuste se ha producido o no? Nos encontramos aquí con la cuestión de la normatividad (política y ética), cuya respuesta no encontramos claramente en Duque, heredando así, a nuestro juicio, los mismos problemas de lo «propio»e «impropio» que encontramos en Heidegger. Aun coincidiendo con Duque en su escepticismo hacia un posible control racional pleno, nos parece insuficiente su propuesta en cuanto a la cuestión normativa sobre qué debemos hacer ${ }^{6}$.

Finalmente, nos parece que la «filosofía de la técnica de la naturaleza» de Duque, sí se hace cargo de las cuestiones históricas y políticas implicadas en la dicotomía natural-artificial, es decir, se ocupa del proceso de construcción o producción de nuestra condición híbrida, de las diversas distribuciones de poder a que ha dado lugar históricamente la técnica, a diferencia de lo que sucede con la metáfora del «cyborg» ${ }^{7}$. Sin embargo, las categorías de «grupo cultural o

6 Michael Sandel, aceptando la dimensión de «indisponibilidad», de «donación», que pone en entredicho la capacidad de diseño absoluto, ha planteado una crítica al perfeccionamiento, buscando criterios éticos. Por ejemplo, respecto a la clonación humana: «En lugar de prohibir la investigación con células madre embrionarias y la clonación destinada a este fin, deberíamos permitir que estas investigaciones sigan adelante en el marco de unas regulaciones que reflejen una contención moral adecuada al misterio que rodea los primeros momentos de la vida humana» (Sandel, 2007: 194).

7 «[...] aunque cada sociedad decide, históricamente, qué entidades materiales deben ser consideradas como naturales, de modo que la variación en el repertorio de cosas o fuerzas se extiende al infinito, hay rasgos comunes en la función que cumple tal repertorio que nos permiten entender lo natural como la sedimentación de invenciones sociotécnicas que se aceptan como recursos dados inmediatamente para una comunidad, olvidando su origen [...] el instrumento, como tal, es una abstracción. Lo concreto, aquello que lo anima y hace útil, es la capacidad (que presupone tanto el lenguaje como una compleja organización social) de construcción de útiles y de reproducción de los saberes./ Tal capacidad, matriz tanto de las fuerzas productivas como de las relaciones de producción, es la técnica. Una variación histórica (pero no necesaria, ni producto de un destino previsto) dentro de algunos grupos sociales de primates ha permitido el lento devenir, sin origen (pues para explicarlo tendríamos que reintroducir como causa lo que aquí aparece como resultado), de la creación de saberes técnicos y, con ellos y por ellos, del hombre [...] No tiene sentido, pues, dentro de la concepción que aquí se defiende, hablar de la Naturaleza como de una entidad (o constelación de fuerzas) previa al 
natural»y «grupo portador de invención» (Duque, 1986: 24; 2019: 28), usadas por Duque en su análisis, resultan, a nuestro juicio, demasiado estrechas como categorías de análisis histórico y filosófico, sobre todo teniendo como horizonte de estudio la entera historia humana. De hecho, podríamos asociar la categoría de «grupo de invención» de nuestra época, a varios de los integrantes de los movimientos trans y post-humanistas, que cumplen bastante bien el perfil dibujado por Duque en $1986^{8}$. Pero más allá de lo adecuado del análisis del propio Duque en Filosofía de la técnica de la naturaleza, nos parece que apunta a una cuestión crucial que él mismo destaca, la ineludible dimensión política de la técnica, la distribución de poder, el establecimiento de dominadores y dominados, de incluidos y excluidos, implicada en la asignación o delimitación de lo natural y lo artificial.

«La Técnica [...] es la colaboración —siempre discorde y en desequilibrio- entre el hombre (no sólo viator, sino instaurador de vías, de vanos y vacíos) y la tierra (en cuanto cierre profundo y retráctil de todo camino). Según esto, la Técnica no es ni ha sido nunca un mero "habérselas" con la Naturaleza (más bien es ella, la Técnica, la que engendra eso que llamamos "Naturaleza": a parte ante, fondo de provisión - lo determinable, en relación con las necesidades abiertas por el hombre-; a parte post, cúmulo de desechos -lo indisponible, en relación con la cerrazón de la tierra-). Desde su inicio - y para nosotros, hombres, ese inicio es el Inicio-, la Técnica se ha configurado como un ejercicio de poder y dominación sobre un territorio por parte de un grupo que, sólo por tener conciencia de esa actividad y reflexionar sobre ella, merece ser considerado como humano. Ahora bien, esa jurisdicción que abre lugares y coloca a las cosas en su sitio implica necesariamente la concentración y la distribución reglada de la violencia, no sobre la tierra, sino sobre los habitantes del territorio (ad intra) y sobre pueblos extranjeros (ad extra), poseedores de las materias primas necesarias para el avance técnico del grupo o que, a la inversa, codician las materias —y las técnicas- de que éste dispone

hombre. Pero, puesto que la actividad técnica de la caza crea, de consuno, al hombre y a la naturaleza, con el mismo sentido puede hablarse de dicha creación de procesos inventivos (y de los estadios subsecuentes) como historia material del hombre y como técnica de la naturaleza./ La naturaleza se va configurando al hilo de la acción del hombre sobre su entorno [...] No hay línea de demarcación entre Naturaleza y Cultura, sino una diferencia de perspectiva de un mismo plexo de referencias» (Duque, 1986: 25-7; 2019: 25-7).

8 En 1986, Duque anunciaba, aunque sin afán predictivo, el nuevo grupo portador de invención, en estos términos: «El nuevo grupo portador de invención es técnico en electrónica (alta especialización) y al mismo tiempo científico (universalidad, garantizada por la red mundial de comunicación computerizada), servidor del Imperio (universalidad) y natural de la periferia (particularidad). O sea, el especialista extranjero es a la vez científico apátrida. No necesita rebelarse, sino seguir trabajando en esa línea (es decir, permitiendo que la contradicción — que pasa por él mismo - se agrave, hasta hacerse insostenible). Por ella puede pasar, quizá, la evolución futura de la Técnica de la Naturaleza» (Duque, 1986: 307). En la edición de 2019 se mantiene este texto (285). A continuación se matiza, sin embargo, luego de 32 años, la "profecía» proferida. No obstante, Duque parece seguir considerando al grupo descrito como el grupo "portador de innovación», aunque algunas de sus características, quizás no esenciales, han cambiado (Duque, 2019: 286-7). 
[...] la actividad técnica no se limita a abrir caminos (por ejemplo, de la aldea a los campos de labrantío, de éstos al bosque cercano), sino que ante todo los fortifica y delimita encerrando el territorio así dominado en una membrana interactiva (de comercio, y también de defensa y ataque: la frontera [...] Si el espacio es producto de la Técnica, ello se debe a que ésta es, ya desde siempre, eminentemente política» (Duque, 2001: 18-20).

En el caso particular del «diseño del cuerpo», la cuestión política se plantea respecto a los ideales y modelos de perfección. En los discursos de transhumanistas y posthumanistas, encontramos en general una acrítica aceptación de modelos que sirven de patrón de medida de la llamada perfección del cuerpo, sin considerar la cuestión política, de distribución de poder, implicada. La supuesta «libre creación», el diseño absoluto o la manipulación del cuerpo, nunca es tal, sino que generalmente preserva y potencia prejuicios y diferencias políticas fundamentales. Desde esta perspectiva, estos movimientos más que progresistas o futuristas resultarían conservadores. Da la impresión que ciberartistas, trans y post-humanistas consideraran que las características y valoraciones asociadas a lo que se llama perfección fueran universales y ahistóricas, las mismas en todo momento y en todo lugar, incluso cuando éstas sean claramente identificables con grupos o individuos socio-históricos específicos, en este caso, el wasp (White anglo-saxon protestan). Tampoco se detienen a pensar ni tomar en cuenta quiénes determinan el modelo que sirve de patrón, ni las relaciones de poder implicadas en él.

«El hombre camaleónico, para quien su cuerpo es una especie de paleta o de plano arquitectónico sobre el cual probar las más variadas figuras...a fin de adaptarse paradójicamente a algo que ya creíamos haber perdido para siempre: el canon occidental (griego, si se quiere) de la figura modélica del cuerpo humano (más bien anoréxico: el ideal del body-fitness). En definitiva: cambios superficiales ad libitum (nunca mejor dicho, puesto que se harán a flor de piel), para intentar diferenciarse individualmente de una conexión en profundidad y tendencialmente total con un entorno casi absolutamente tecnificado (hasta el extremo de la recreación tecnológica de la "naturaleza virgen": selvas de plástico, al igual que ya hoy adornan por doquier nuestras ciudades de plástico)»(2007b).

El diseño del cuerpo apunta a modelos que nunca son puramente ideales, que por tanto implican acciones y construcciones, ideas y conceptos, normas y elecciones, nunca un acto de pura libertad de equilibrio. Antes de plantearse el deseo del diseño del cuerpo, habría que preguntarse por qué ciertas características específicas parecen deseables. No solo en sentido abstracto. El modelo que se busca aplicar al diseñar el cuerpo no es neutro ni política ni moralmente, no cayó simplemente del cielo, ni es universal ni a-histórico (tal como ya puso de relieve Foucault con su noción de biopolítica). Está constituido de proyectos, elecciones, supuestos, prejuicios, nociones de lo normal y de lo anormal, de lo deseable y lo no deseable, de lo saludable y de lo enfermo, de la distribución de poder entre grupos que dominan y grupos dominados o excluidos (como muestran en clave distópica películas como In Time, Repo Man 
y Gattaca). No basta con decir que se busca una situación de posthumanidad porque se busca evitar la enfermedad, es fundamental establecer qué enfermedades, en particular se buscan evitar, y de quién o para quién son tales enfermedades. Esto ya es muy claro hoy en día. Por ejemplo, el discurso políticamente correcto de las farmacéuticas, que afirma sólo la producción de medicamentos para curar enfermedades (algo a lo que nadie en su sano juicio se opondría). No obstante, no se explicita las enfermedades de quién. De esta manera, se producen medicamentos contra la depresión y la obesidad (afecciones propias de países «desarrollados»), pero no contra el mal de Chagas o la malaria (enfermedades propias del «tercer mundo»). Un ejemplo del carácter abstracto de las proclamas post y transhumanistas, lo leemos en el punto 5 de la «Declaración Transhumanista» (versión de 2012), en donde se afirma: «La reducción de los riesgos existenciales y el desarrollo de los medios para la preservación de la vida y la salud, el alivio del sufrimiento grave y la mejora de la previsión y de la sabiduría humanas deberían ser promovidos como prioridades urgentes, y ser financiados fuertemente» (More y Vita-More, 2013: 54). Los riesgos existenciales, la vida, la salud, el sufrimiento, ¿de quién/es? La declaración no responde a esta pregunta.

Toda tecnología o técnica, implica de manera inextricable una distribución de poder, un establecimiento de límites que determinan y distribuyen a los dominantes y los dominados. Se responde así afirmativamente la pregunta que hacía Langdon Winner casi de manera contemporánea a la elaboración de Filosofía de la técnica de la naturaleza de Duque: ¿tiene política la tecnología? (Winner, 1983). Las tecnologías no son meramente instrumentales (Duque, 1995: 37), no son neutrales desde una perspectiva política. Esto queda generalmente en la oscuridad en las propuestas trans y post-humanistas. O mejor dicho, queda oculta bajo un excesivo optimismo tecnófilo. No se preguntan quién establece, ni cómo se establecen, las características que determinan la valoración positiva de la intervención técnica del cuerpo, ¿quién establece lo que se mienta al decir de algo que es perfecto? Tampoco se ponen de relieve las asimetrías de poder que las innovaciones tecnologías pueden producir.

\section{CONCLUSIONES}

La elaboración de la concepción del cuerpo como máquina durante los siglos XVII y XVIII, no quedó simplemente en una cuestión metafórica, sino teórica y práctica. En este contexto tecnológico, la comprensión de la naturaleza de los seres vivos y los cuerpos orgánicos como mecanismos o máquinas automáticas, la concepción del mundo como un gran mecanismo de relojería, y de Dios como relojero que ha diseñado este mundo y lo ha puesto en movimiento, parecía desvelar el secreto funcionamiento de la naturaleza. Esta comprensión del cuerpo como máquina da lugar en nuestra época a la noción de cyborg, que a partir de Donna Haraway se concibe como concepto filosófico 
para comprender la condición humana, y también juega un rol clave en la proliferación de tendencias transhumanistas y posthumanistas que ven en los desarrollos científico-técnicos la vía para superar las limitaciones del cuerpo, que parece quedar obsoleto.

Artistas del cuerpo como Stelarc y Orlan, coinciden con trans y post-humanistas en la obsolescencia del cuerpo, y ponen en evidencia su supuesto carácter absolutamente manipulable y controlable, la posibilidad de diseño libre del cuerpo, con sus performances de body art y arte carnal. El filósofo español Félix Duque critica las propuestas de Stelarc y Orlan y por extensión las de transhumanistas y posthumanistas. Estas críticas son principalmente tres: dualismo y rechazo del cuerpo que se escondería bajo una supuesta valoración del mismo; sueño de control absoluto que implica una imagen dualista clásica de cuerpo-mente, y que concibe el cuerpo como ente material puramente pasivo y la mente o la voluntad como absolutamente libres, con una libertad de indiferencia, es decir, sin condicionamientos, ocultándose así los condicionamientos, determinaciones y prejuicios que están en la base de la decisión de diseñar y de los ideales de perfección que sirven de modelo; y por último, el dejar en las sombras las decisiones normativas implicadas en la elección de ciertas características, patrones o valores como signos de perfección, y universalizar este modelo de manera completamente acrítica. En el fondo se trata de un triple ocultamiento basado en la «apelación a lo natural».

Aunque transhumanistas y posthumanistas parecieran rehuir tal apelación, en cuanto buscan transformar o reformar técnicamente lo natural, parten de una concepción esencialista de la misma, y de la propia técnica, que no considera su dimensión «física», espontánea, no controlable, indisponible. Esto los lleva a hipostasiar ciertas características específicas y propias de un momento histórico específico, como propias de una suerte de naturaleza humana universal, que de manera completamente acrítica se considera buena. Este conjunto de características coinciden justamente con aquellas predominantes en las sociedades llamadas desarrolladas. Así pues, estas posiciones acuden a una apelación encubierta a lo natural en tanto garante de sus valoraciones y prescripciones, en tanto garante de sus posiciones normativas, sin cuestionarse siquiera para quién son esas características naturales u obvias y cómo han llegado a serlo, es decir sin considerar la cuestión política implicada. Estas posiciones dualistas en el fondo, se basan en última instancia en una concepción errada de la técnica, que aparece como una posición unilateral, separada y opuesta a lo natural. La noción de «técnica de la naturaleza» de Duque puede ayudar a superar estas dificultades y plantear la dicotomía natural-artificial en términos más adecuados, incluyendo la cuestión de los límites y la cuestión política, aunque carece a nuestro juicio de un claro posicionamiento respecto a la cuestión normativa, de qué debemos hacer. 


\section{BiBLIOGRAFÍA}

Aguilar, T. (2008). Ontología cyborg. El cuerpo en la nueva sociedad tecnológica. Barcelona: Gedisa.

Broncano, F. (2009). La melancolía del ciborg. Barcelona: Herder.

Broncano, F. (2006). Entre ingenieros y ciudadanos. Filosofía de la técnica para días de democracia. Montesinos.

Broncano, F. (2000). Mundos artificiales. Filosofía del cambio tecnológico. México D.F.: Paidós.

Clynes, M.; Kline, N. (1960). «Cyborgs and Space». Y en: Astronautics, Vol. 5, n 9, pp. 26-27, 74-76.

Descartes, R. (1990). El tratado del hombre. Madrid: Alianza.

Diéguez, A. (2017). Transhumano. La búsqueda tecnológica del mejoramiento humano. Barcelona: Herder.

Duque, F. (2019). Filosofía de la técnica de la naturaleza ( $3^{\mathrm{a}}$ edición corregida y aumentada). Madrid: Abada.

Duque, F. (2008). Habitar la tierra. Medioambiente, humanismo, ciudad. En: Madrid: Abada.

Duque, F. (2007a). «Del cuerpo crucificado a los cuerpos posthumanos». En: Eikasia. Revista de Filosofía, vol. II, n 8, pp. 1-43.

Duque, F. (2007b). «¿Cuál será el futuro del cuerpo humano?». Y en: Revista la $U, \mathrm{n}^{\circ} 29$, Universidad San Juan, Argentina, disponible online en: http://www.revista.unsj.edu. ar/revista29/felix_duque.htm

Duque, F. (2003). «De cyborgs, superhombres y otras exageraciones». Y en: D. Hernández (ed.), Arte, cuerpo, tecnología. Salamanca: Universidad de Salamanca, pp. 167187.

Duque, F. (2002). En torno al humanismo. Heidegger, Gadamer, Sloterdijk, Madrid: Tecnos.

Duque, F. (2001). Arte público y espacio político. Madrid: Akal.

Duque, F. (2000). Filosofía para el fin de los tiempos. Tecnología y apocalipsis. Madrid: Akal.

Duque, F. (1995). El mundo por de dentro. Ontotecnología de la vida cotidiana. Barcelona: Del Serbal.

Duque, F. (1986). Filosofía de la técnica de la naturaleza. Madrid: Tecnos.

Durán, R. (2017). «Espontaneidad, cuerpo y organismo en Leibniz». Y en: R. Casales y J. M. Castro (comps.), La modernidad en perspectiva. A trescientos años del fallecimiento de Leibniz. Granada: Comares, pp. 79-89.

Ferry, L. (2017). La revolución transhumanista. Cómo la tecnomedicina y la uberización del mundo van a transformar nuestras vidas. Madrid: Alianza.

Gray, C.H.; Mentor, S.; Figueroa-Sarriera, H. (1995). "Cybergology. Constructing the Knowledge of Cybernetic Organism». Y en: D. Haraway and C. Hables-Gray, The Cyborg Handbook. New York: Routlegde, pp. 1-15.

Haraway, D. (1995). «Manifiesto para cyborgs: ciencia, tecnología y feminismo socialista a finales del siglo XX». Y en: Ciencia, cyborgs y mujeres. La reinvención de la naturaleza. Madrid: Cátedra, pp. 251-311.

Hottois, G. (2014). Le transhumanisme est-il un humanisme? Bruxelles: Académie Royale de Belgique.

López, D. (2015). Bioarte. Arte y vida en la era de la biotecnología. Madrid: Akal.

More, M.; Vita-More, N. (eds.) (2013). The Transhumanist Reader. Wiley-Blackwell. 
Noble, D. (1999). La religión de la tecnología. La divinidad del hombre y el espíritu de invención. Barcelona: Paidós.

Orlan (2000). «El cuerpo del artista como territorio del arte». En: Mead Electronic Journal, $\mathrm{n}^{\circ}$ 5, disponible online en: http://www.geifco.org/Ediciones_PRO/instalarLoReal/ejournal5.pdf

Orlan (s/f). «Arte carnal». Y disponible en página web de la artista: http://www.orlan.eu/ bibliography/carnal-art/

Riskin, J. (2016). The Restless Clock. A History of the Centuries-Long Argument over What Makes Living Things Tick. Chicago: The University of Chicago Press.

Sandel M. (2007). Contra la perfección. La ética en la era de la ingeniería genética. Barcelona: Marbot.

Sterlarc (S./F.). «Absent Bodies», «Obsolete Bodies», «Redesigning the Body». Y disponibles online en la web de Stelarc, sección «Earlier Statements»: http://stelarc. org/?catID $=20317$

Stelarc (S./F.). «Excess and Indifference. Alternate Body Architectures», disponible online en la web de Stelarc: http://stelarc.org/documents/ExcessandIndifference2.pdf

Winner, L. (1983). «¿Tienen política los artefactos?». Y en: La ballena y el reactor. Una búsqueda de los límites en la era de la alta tecnología, 1987, Barcelona: Gedisa, pp. 25-36.

Winner, N. (1948). Cybernetics Or Control and Communication in the Animal and the Machine, MIT Press.

Universidad de Playa Ancha, Valparaíso - Chile

Ronald Durán AlLimant

ronald.duran@upla.cl

[Artículo aprobado para publicación en febrero de 2020] 